\title{
Simulation analysis of thermal performance of the solar air/water collector by using computational fluid dynamics
}

\author{
Jafer Shandal ${ }^{1}$, Qahtan A Abed ${ }^{2, *}$, and Dhafer M. Al-Shamkhee ${ }^{3}$ \\ ${ }^{1,3}$ Engineering technical college/ Najaf, Al - Furat Al- Awsat Technical University, 31001, Iraq \\ ${ }^{2}$ Technical Institute/ Al-Rumaitha, Al - Furat Al- Awsat Technical University, 31001, Iraq
}

\begin{abstract}
Utilizing solar energy has received a giant activity by energy applications into distinctive states within the world. The sun is regarded strong supply providing uninterrupted coherent energy. In this research, simulation study has been done to estimate the performance of dual purpose solar collector (DPSC). Flat plate dual purpose solar collector with dimensions (194 cm length, $95 \mathrm{~cm}$ width and $14 \mathrm{~cm}$ thickness) has been used for heating the air and water for different using. Rectangular fins are used in air duct to increase heat transfer coefficient in air heater part. COMSOL Multiphysics 5.4 computer program has been used to calculate the theoretical results. Many parameters such as a different flow rate and temperatures for the inlet working fluids are investigated.
\end{abstract}

\section{Introduction}

One of the most serious matters in the world is energy. As we know, there are many sources to get the energy. The most important of which is the most common fossil fuel, but, because of the many problem caused by fossil fuel, the attention have been given to searchers for another sores. Solar energy is considered more renewable energy using thermal collectors. These collectors are most common type of solar energy applications. Assari et al [1] Studied an experimental and theoretical investigation performance of two working fluid solar collector to product hot air and hot water. To improve the performance of the hybrid air and water collector, the authors used various air forms of air ducts. They showed that the rectangular fin types have better performance. Nematollahi et al [2] Published an experimental study to investigate the two different types of flat solar collector's effectiveness. Using dual purpose solar collector (DPSC) decreases costs and required space. Venkatesh and Christraj [3] Carry out an experimental study on same collector which design by M.R. Assari et al. But in this study, the authors studied dray a mixture of three vegetable types; dill the first one, parsley second and the last one was coriander at constant air and water flow rates. The obtained results were evaluated with other results had been obtained from the solar drier collector have an electrical heater. The results appear that the dryer solar collector with an electrical heater has $20{ }^{\circ} \mathrm{C}-30{ }^{\circ} \mathrm{C}$

\footnotetext{
* Corresponding author: qahtan.abed@atu.edu.iq
} 
temperature more than the dryer solar collector without a heater. Ref.[4] Conducted an experimental work to increase solar collector's efficiency by investigating a combined solar collector. The testing of this system included as solar water and air heater in two cases under the load conditions. The work results show that the solar water heater with $0.015 \mathrm{~kg} / \mathrm{s}$ water mass flowrate has thermal efficiency equal to $67.69 \%$, while solar air heater with $0.0104 \mathrm{~kg} / \mathrm{s}$ has an $85 \%$ thermal efficiency. However, the rate of thermal efficiency for the hybrid solar collector was 70\%. Ref.[5] Design and study experimentally and theoretically of the dual solar collector. Deferent tests are done to investigate dual solar collector efficiency and outlet temperature or both fluids. The authors were found perfect agreement between the theoretical and experimental results. They showed a minimum fluid flow rate it cases to enhance the temperature and efficiency. The solar air with the triangular duct can be providing enhance in the collector efficiency and fluid temperature near to $10 \%$ more of the other collectors. The dual solar collector has many interesting benefits. This collector is modifying from the classic geometry to the solar water heater with L-shaped fins fixed in the absorber plate [6]. It's working to raise the amount of heat transfer in air heater side. The authors offer that the DPSC can increase the water $(100 \mathrm{~L})$ temperature around $30^{\circ} \mathrm{C}$ during the day. In water heating, daily efficiency reached $50 \%$. While the daily efficiency of air heating reached 52\%. Ref.[7] Conducted a numerical simulation work on the DPSC integrated with a porous media. The simulation is carry out by ANSYS 13 software program. The suggestion system is compared with dual solar collector designed by M.R. Assari, et al. The compared show that the increase in the temperature rise is gained for the working fluids (air and water) under different operating conditions. Ref.[8] Carried out an experimental and theoretical study to investigate the DPSC incorporated with the walls. This study conducted to controlled and non-controlled the indoor temperature. The numerical and experimental results were validated. The experimental shows that the temperature of the air inside the room can be increased by about $3.43{ }^{\circ} \mathrm{C}$ during the winter season, while the power consumption of the DPSC was $3.5 \mathrm{KWh}$, when setting the air temperature inside the room to $18^{\circ} \mathrm{C}$. The numerical results show that means daily thermal efficiency of DPSC was 44.3\%. Ref.[9] Studied flat plate solar collector experimentally and theoretically. The three modes had been presented, air heating, water heating and air-water compound heating. The mathematical model is analysis the effect of working fluid mass flow rate on the behaviour of air and water heating modes. The thermal collector efficiency is $51.3 \%$ and $51.4 \%$ for the first and second mode. In the third mode, the rate of the collector efficiency equal to $73.4 \%$. Also, the work results present that the fluid flow rate has affected significantly on fluid outlet temperature and collector efficiency. In the first mode and a second mode, the authors had been recommended the airflow rate reached 0.02 $\mathrm{kg} / \mathrm{s}-0.25 \mathrm{~kg} / \mathrm{s}$ and the water flow rate reached $0.06 \mathrm{~kg} / \mathrm{s}-0.08 \mathrm{~kg} / \mathrm{s}$ respectively. the solar hybrid collector has been studied experimentally with dehumidification system by Ref.[10]. The system has tested with different value of the airflow rate $(50.4 \mathrm{~kg} / \mathrm{h}-64.8 \mathrm{~kg} / \mathrm{h})$ and water flow rate $(60 \mathrm{~kg} / \mathrm{h}$ to $120 \mathrm{~kg} / \mathrm{h})$. The authors concluded that the maximum productivity of the distillate during the day of $15.23 \mathrm{~kg} / \mathrm{m}^{2}$ and $14.14 \mathrm{~kg} / \mathrm{m}^{2}$ was obtained from the concave system and convex system respectively. The total thermal efficiency of the system ranges about $68 \%$ for the collector integrated with turbulators. The purpose of this study is to prove the enhancement of a DPSC by computational fluid dynamics. A threedimensional CFD analysis is validated with the previous studies for the DPSC. This collector combined the employment; therefore it can reduce the cost and working area. The collector geometry and weather conditions were studied then 


\section{Description of the system}

The performance of any solar thermal collector may be developed by modified conventional design to air-water solar collector simultaneously. The suggested collector used as boundary conditions detailed by Assari et al [1]. The modified design of air-water solar collector is decrease cost and required space. In this study, the parts of solar air-water collector used are shown in figure 1 . The main parts of the suggested dual purpose solar airwater collector are metal pipes and the absorber plate. The absorber plate $(94 \times 194 \times 1 \mathrm{~mm})$ consists of triangular fins which have angle equal to ${ }^{0} 60$.

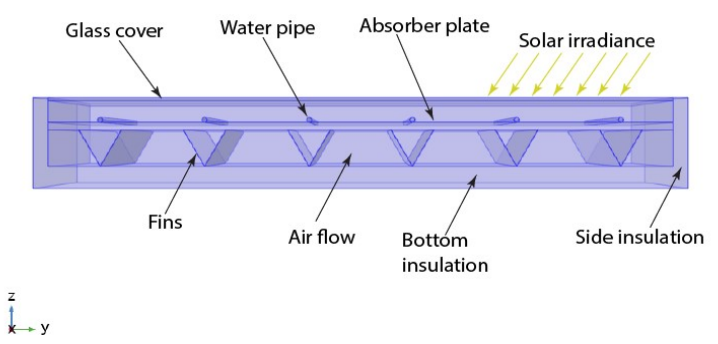

Fig.1. Scheme sectional view of the air-water heater collector model.

The collector is consisting of flat plate solar collector with two parts; one of them for water heating has water pipes, inlet water side and outlet water side. These pipes bonded on the absorber plate. While the other part is air heating with triangular fins to increase the heat transfer coefficient. Table 1 presents the details of geometrical parameters and materials used for the suggested collector.

Table 1. Dual purpose solar air water collector geometric specification

\begin{tabular}{|c|c|c|c|}
\hline \multirow{2}{*}{ Collector component } & Material & Quantity & Value \\
\hline \multirow{2}{*}{ Absorber plate } & \multirow{3}{*}{ Aluminium } & High & $0.94 \mathrm{~m}$ \\
\cline { 3 - 4 } & & Width & $1.94 \mathrm{~m}$ \\
\cline { 3 - 4 } & Zinc & Thick & $0.001 \mathrm{~m}$ \\
\hline Water pipes & Aluminium & Triangle with the angle of & $60^{\circ}$ \\
\hline Fins & Float glass & Thick & $4 \mathrm{~mm}$ \\
\hline Glazing & Glass wool & Thick & $5 \mathrm{~cm}$ \\
\hline Bottom insulation & Silicon rubber & Thick & $2 \mathrm{~cm}$ \\
\hline Sid insulation & Stainless steel & Thick & $1 \mathrm{~mm}$ \\
\hline Main frame & & &
\end{tabular}

\section{Modeling of DPSC}

The geometry of the dual purpose solar air-water collector is present in Fig. 1. They operate and performance of the solar air-water collector were modelled by using the COMSOL Multiphysics software. It is consists of an absorber plate, water pipe, air channel and thermal insulation layers. The solar irradiance is passing through the glass cover. Therefore is incident on the absorber plate and transformed into internal thermal energy. 
The ambient air at temperature $T_{a m b}$ is entering through the air channel, it is streaming down the absorber plate and the water pipe, and it gets the heat by two sources; the first one from the absorber plate and the second from triangular fins. At the same time, the water is flowing at inlet temperature $T_{w, i n}$ through the pipes; it's heating by the absorber plate and pipe surface. The first modelling point consists of present components of the DPSC. They are shown in Fig. 2. These components correspond to four domains: the water pipes (A), absorber plate (B), triangular fins (C) and air channel (D).

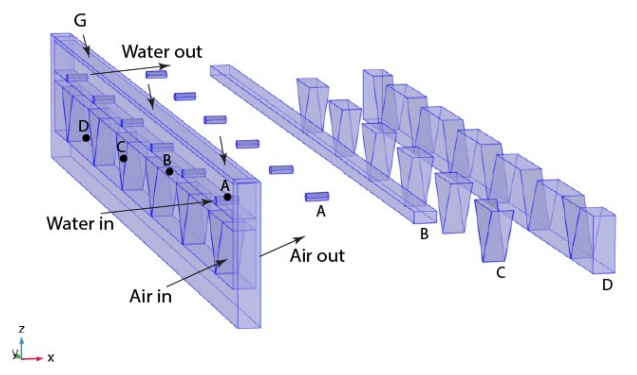

Fig. 2. Shows the main components of the DPSC. (A) water pipes, (B) absorber plate, (C) triangular fins, (D) air channel

The water flow inside the circular pipes was laminar flow type. It is depending on the Reynolds number (2000 to 4000). This is defined as shows:

$$
R_{e}=\frac{\rho D V}{\mu}
$$

Where: $\rho$ and $V$ is the density and velocity of working fluid (water), respectively, $D$ circular pipe diameter and water dynamic viscosity.

\subsection{Geometry and grid generation}

The system modeling and simulation was carried out by COMSOL Multiphysics 5.4. It is a good environment to solve set of equation systems of unsteady-state or stationary in space partial differential equations in two or three dimensions. The primary stage of the built DPSC model is the type of mesh. Therefor many types of CFD mesh have been created (see figure 1). The type and number of mesh are larger in this model where fluid velocity gradients, temperatures are presumed to be significant. Figure 3 . shows the mesh close to the water pipes, the triangular fins and the absorber plate is small sizes to the accuracy of the solution.

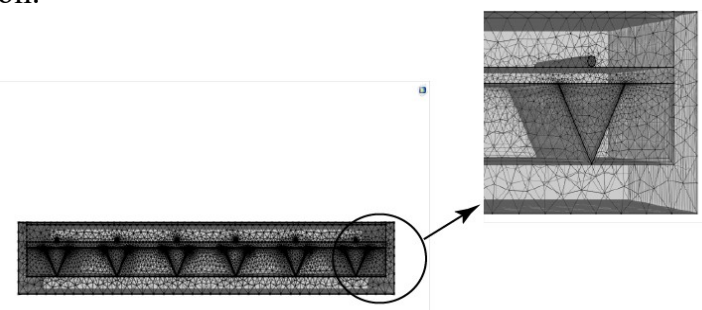

Fig. 3. The mesh type for the DPSC model. 
The complete mesh consists of 1186525 domain elements, 186108 boundary elements, and 20144 edge elements. The assumptions used in simulation analyses of air-water solar collector are listed below:

- The solar air-water collector is 3D flow.

- The mean temperature value for all metal parts of the collector $\left(T_{p, m}\right)$.

- The flow of the working fluid is laminar

- Neglecting the heat losses by convection and radiation from the metal parts.

\subsection{Governing equations}

The equations using in the fluid flow is incompressible Navier-Stokes equations. The governing equations of modelled:

- Continuity equation

$$
\rho\left(\frac{\partial u}{\partial x}+\frac{\partial v}{\partial y}+\frac{\partial w}{\partial z}\right)=0
$$

Where $\rho$ is fluid density $\left(\mathrm{kg} / \mathrm{m}^{3}\right), u, v, w$ are velocity vectors $(\mathrm{m} / \mathrm{s})$.

- Momentum conservation equation

$\mathrm{x}$ - direction momentum equation

$$
\rho\left(\frac{\partial u}{\partial t}+u \frac{\partial u}{\partial x}+v \frac{\partial u}{\partial y}+w \frac{\partial u}{\partial z}\right)=-\frac{\partial p}{\partial x}+\mu\left(\frac{\partial^{2} u}{\partial x^{2}}+\frac{\partial^{2} u}{\partial y^{2}}+\frac{\partial^{2} u}{\partial z^{2}}\right)
$$

$\mathrm{y}$ - direction momentum equation

$$
\rho\left(\frac{\partial v}{\partial t}+u \frac{\partial v}{\partial x}+v \frac{\partial v}{\partial y}+w \frac{\partial v}{\partial z}\right)=-\frac{\partial p}{\partial y}+\mu\left(\frac{\partial^{2} v}{\partial x^{2}}+\frac{\partial^{2} v}{\partial y^{2}}+\frac{\partial^{2} v}{\partial z^{2}}\right)
$$

z- direction momentum equation

$$
\rho\left(\frac{\partial w}{\partial t}+u \frac{\partial w}{\partial x}+v \frac{\partial w}{\partial y}+w \frac{\partial w}{\partial z}\right)=-\frac{\partial p}{\partial z}+\mu\left(\frac{\partial^{2} w}{\partial x^{2}}+\frac{\partial^{2} w}{\partial y^{2}}+\frac{\partial^{2} w}{\partial z^{2}}\right)
$$

- Energy conservation equation

$$
\text { ค. } C_{p}\left(\frac{\partial T}{\partial t}+u \frac{\partial T}{\partial x}+v \frac{\partial T}{\partial y}+w \frac{\partial T}{\partial z}\right)=k\left(\frac{\partial^{2} T}{\partial x^{2}}+\frac{\partial^{2} T}{\partial y^{2}}+\frac{\partial^{2} T}{\partial z^{2}}\right)
$$

Where $C_{p}, T, \mu$ and $k$ are specific heat of fluid (J/(kg.K)), fluid temperature (K), dynamic viscosity of fluid $(\mathrm{kg} /(\mathrm{m} . \mathrm{s}))$, and thermal conductivity of fluid $(\mathrm{W} /(\mathrm{m} . \mathrm{K})$ ) respectively.

\subsection{Initial conditions}

The above equations have been solved by the following initial conditions.

At first the initial temperature of the initial air, water inlet and absorber plate equal the ambient air temperature at the starting time (which $\mathrm{t}=0$ ).

$$
T_{\text {air } \left., w, p^{(x, y, z, t}=0\right)}=T_{a m b^{(t=0)}}
$$

While, the initial air and water velocity field (in $3 \mathrm{D})$ are equal to zero:

$$
u_{\text {air }, w}(x, y, z, t=0)=v_{\text {air }, w}(x, y, z, t=0)=w_{\text {air }, w}(x, y, z, t=0)=0
$$




\subsection{Boundary conditions}

The constant inlet water temperature, however the inlet air temperature is equal to ambient temperature, while the inlet pressure equals the measured atmospheric pressure:

$$
\begin{gathered}
T_{w}(x=0, y, z, t)=20^{o} C \\
T_{a i r}(x=0, y, z, t)=T_{a m b}(t) \\
p(x=0, y, z, t)=p_{a t m}(t)
\end{gathered}
$$

The air channel walls which do not in contact with the absorber plate or the has good thermal insulation, also there are No-slip condition at the air chanal walls, therefore

$$
\begin{gathered}
-k_{\text {air }} \nabla T=0 \\
u_{\text {air }}(x, y, z, t)=v_{\text {air }}(x, y, z, t)=w_{\text {air }}(x, y, z, t)=0
\end{gathered}
$$

\section{Model validation}

In order to identify differences between the experimental results of the previous work and the simulation results of this study, prepared the chart described below which shows the absorber plate temperature of the two studies and change with time. We note good convergence between the two results. (See fig.4)

Two indicators have been used to show the model accuracy: the first is Mean Bias Error (MBE) as follows:

$$
M B E=\frac{1}{n} \sum_{i=1}^{n}\left(T_{i, c o m p}-T_{i, \exp }\right)
$$

where: $T_{i, \exp }$ and $T_{i, \text { comp }}$ are the experimented and computed absorber plate temperature, respectively, while $n$ refer to the total number of values.

While the second indicators is Root Mean Square Error (RMSE) is defined as:

$$
R M S E=\sqrt{\frac{1}{n} \sum_{i=1}^{n}\left(T_{i, \text { comp }}-T_{i, \exp }\right)^{2}}
$$

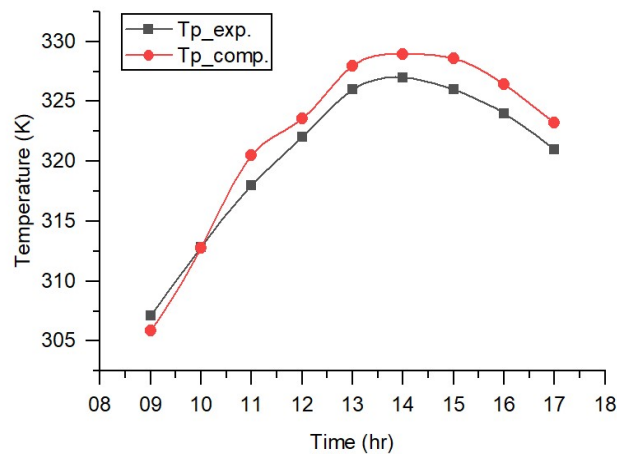

Fig. 4. Computed and experimental results acquired during 21 May 2018 for a DPSC.

We note a good convergence between the experimental results and the simulation results; this is due to the adoption of the same conditions in simulation. 


\section{Result and discussion}

The solar air-water collector under test was directed southward in the city of Najaf, Iraq (latitude $32^{\circ} 02^{\prime}$, longitude $44^{\circ} 20^{\prime}$ ) and the tilt angle is $32^{\circ}$. Three days of the year, summer, winter and spring data were used to compare results. The simulation results for the modified the DPSC is presented in this section. The meteorological (weather condition) and operation parameters (outlet temperature) during three days on January, May and July are shown in figures $5-7$.

Figure 5 (A) shows that during an experimental winter (5 January) day the solar irradiance is lower on the dual purpose solar collector surface than the other two days.

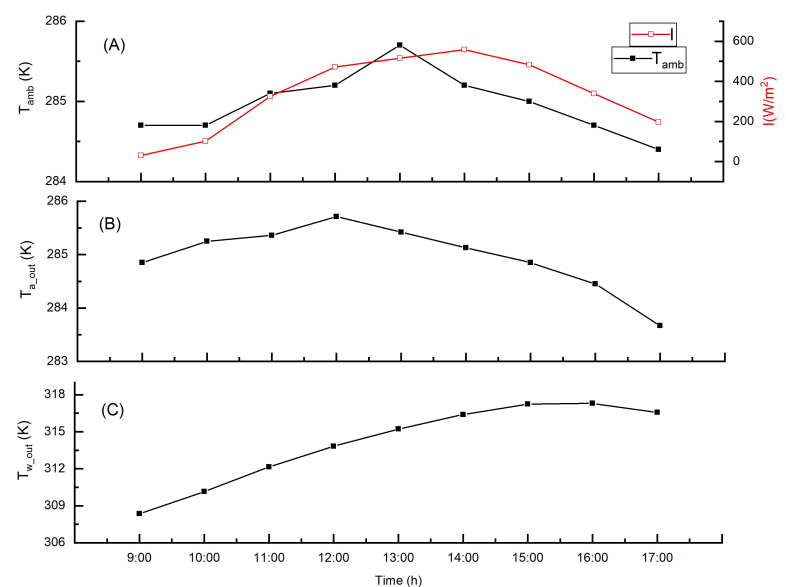

Fig. 5. (A) Solar irradiance and ambient temperature on cloudy day 5 Jan. 2018, (B) outlet air temperature and $(\mathrm{C})$ outlet water temperature

The simulation outlet water and air temperatures increases have a time variation that is analogous to the direct solar irradiance curve (like Fig. 5B and Fig. 5C). Next figure 6, the DPSC operation during clear sky day on May is presented. The outlet water and air temperatures are smaller in the morning for the DPSC than the end of the day. This meaning lower solar irradiance on the morning and accumulated the heat in the collector at the end of the day.
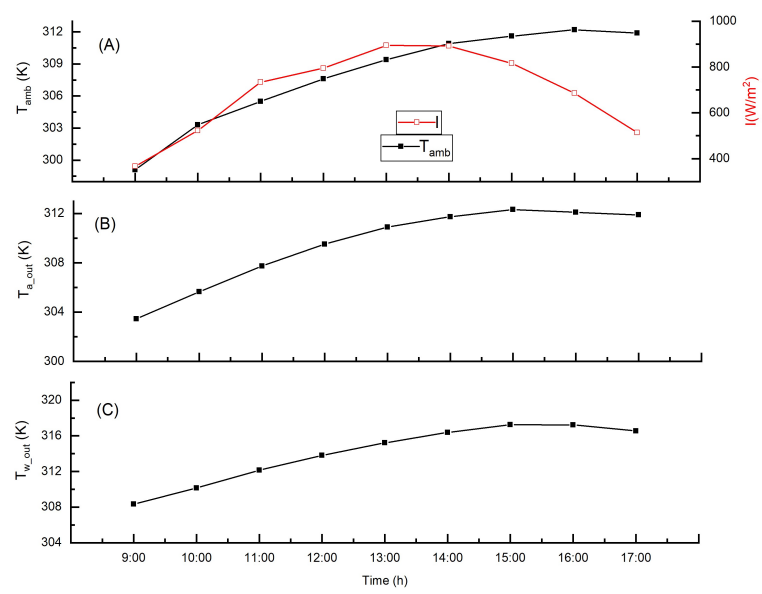

Fig. 6. (A) Solar irradiance and ambient temperature on nearly clear sky day 1 May 2018, (B) outlet air temperature and (C) outlet water temperature 
The contours draw of the DPSC temperatures obtained from the 3D CFD analysis are described in figures 7,8 and 9. They are presenting the temperature gradient for the two working fluids (water and air) for three days. The contour DPSC of magnitudes temperatures assist to understand the thermal heat phenomenon of the solar collector during the day.

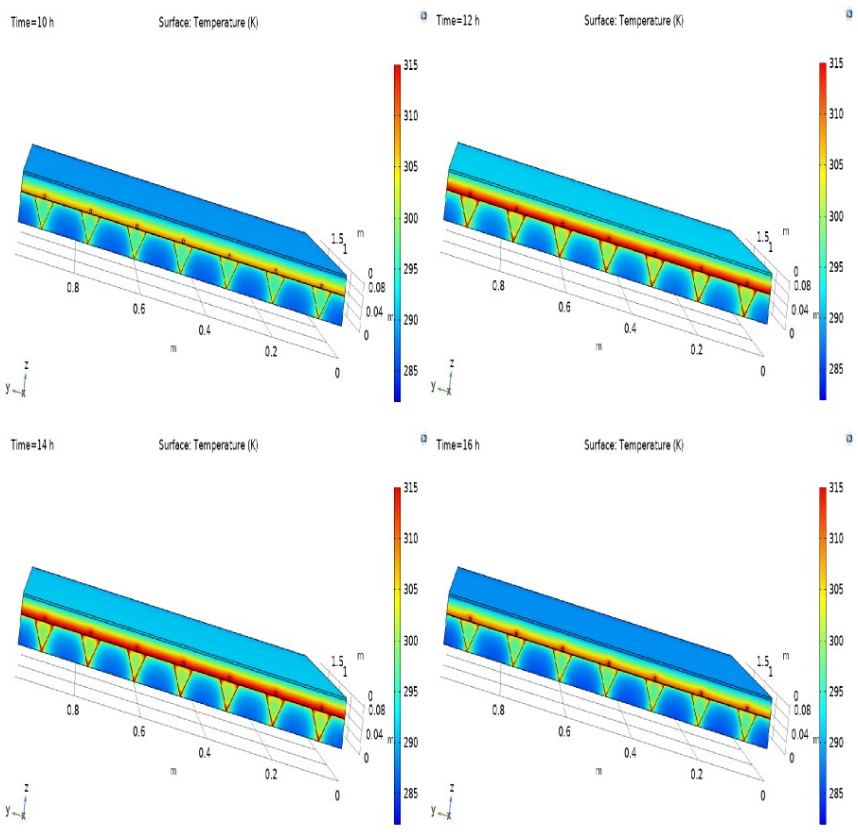

Fig. 7. Temperature distribution for the fluids stream along the flow at summer season

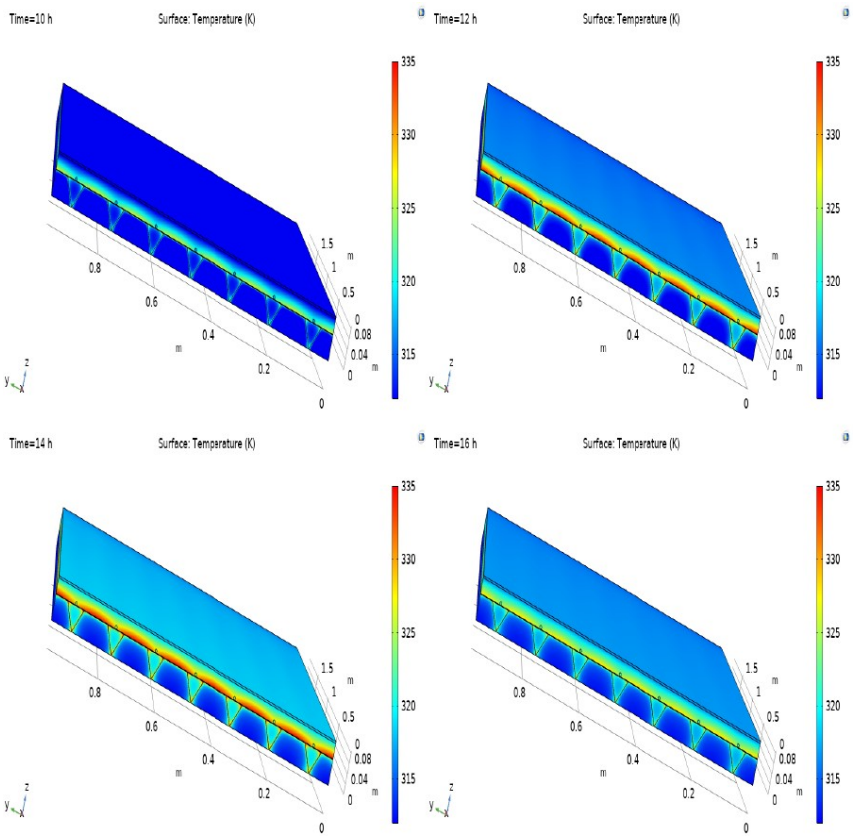

Fig. 8. Temperature distribution for the fluids stream along the flow at winter season 
The fluid temperature distribution in a DPSC with various times during the day has been shown in Fig. 9. At the beginning of the day, the absorber plate and water pipe temperature are higher than in other parts. The absorber plate sends heat energy to the water pipes and air channel that transmit this energy to water and air. They observed that higher temperature values are expected at 2 PM for three days.

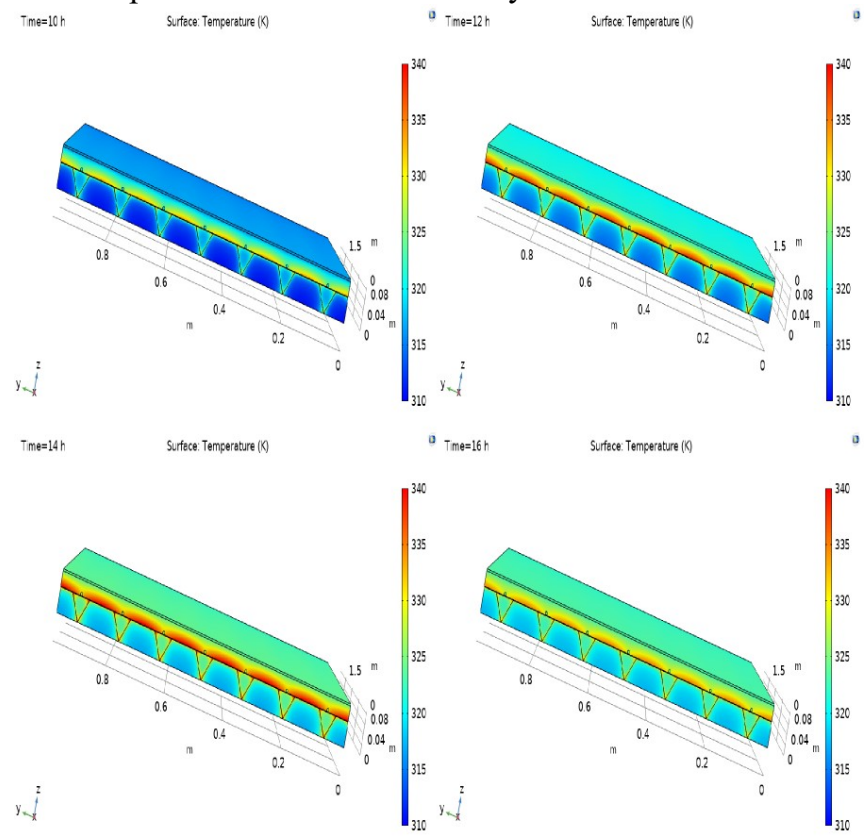

Fig. 9. Temperature distribution for the fluids stream along the flow at spring season

The above figures show that the temperature distribution in the DPSC three days for three seasons. The maximum temperature about a $(341 \mathrm{k}, 319 \mathrm{~K}$ and $335 \mathrm{~K})$ in the absorber plate in Summer, winter and Spring respectively. It starts with the gradual escalation with the solar radiation increase. The distribution of air velocity is showing in figure 10. Air velocity varies between $0.02 \mathrm{~m} / \mathrm{s}-0.18 \mathrm{~m} / \mathrm{s}$. The velocity of air near the fins wall is closed to zero; it then gradually increases until it reaches the greatest value in the middle of the fins. Air velocity effects on the air outlet temperature, when the velocity increases, the air outlet temperature decreases.

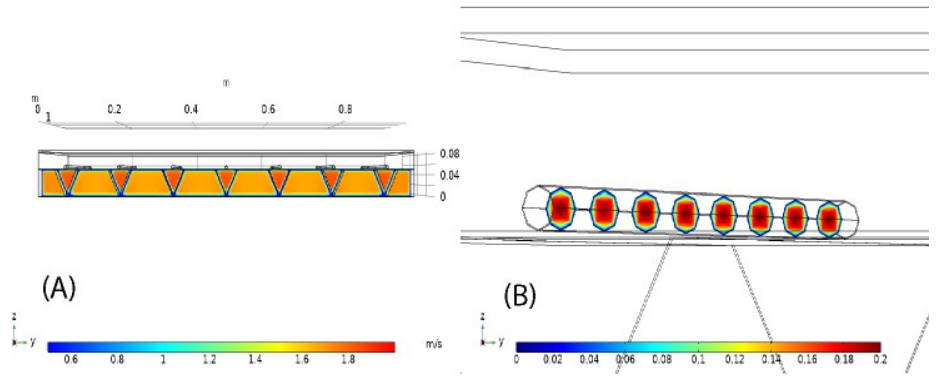

Fig. 10. The fluid velocity distribution inside DPSC: (A) air, (B) water.

Figure 10 shows the flow of water in the pipes. Because the velocity is equal in all pipes according to the simulation assumptions, we took one pipe to show the velocity change. 
The velocity in the pipe is fully developed where the greatest velocity is concentrated in the middle.

\section{Conclusion}

A simulation analysis has been study to investigate the thermal performance of the solar airlwater collector by using computational fluid dynamics was consider in this paper. The system modelling and simulation studies have been performing by using software COMSOL Multiphysics 5.4. Temperature and velocity of fluid streams are present under time dependent situation. The reduction of airflow by fins increases the outlet air temperature. Parametric analyses on the system are fluid flow rates, solar radiation and water inlet temperature. When increases water inlet temperature, efficiency decreases, other ways the efficiency increases with increases the mass flow rate. The differences between actual and simulation results for the dual-purpose solar collector is $2.23 \%$. The higher efficiency was $69.42 \%$ in summer.

\section{References}

1. M. R. Assari, H. Basirat Tabrizi, and I. Jafari, 'Experimental and theoretical investigation of dual purpose solar collector', Sol. Energy, 85, (2011).

2. O. Nematollahi, P. Alamdari, and M. R. Assari, 'Experimental investigation of a dual purpose solar heating system', Energy Convers. Manag., 78, (2014).

3. A. Mohajer, O. Nematollahi, M. M. Joybari, S. A. Hashemi, and M. R. Assari, 'Experimental investigation of a Hybrid Solar Drier and Water Heater System', Energy Convers. Manag., 76, (2013).

4. R. Venkatesh and W. Christraj, 'Experimental Investigation of Multipurpose Solar Heating System', J. Energy Eng., 141, 3, (2013).

5. H. K. and M. M. M.R. Assari, H. Basirat Tabrizi, 'Design and Performance of DualPurpose Solar Collector', no. August, (2007).

6. J. Ma, W. Sun, J. Ji, Y. Zhang, A. Zhang, and W. Fan, 'Experimental and theoretical study of the efficiency of a dual-function solar collector', Appl. Therm. Eng., 31, 10, (2011).

7. A. Venu and P. Arun, 'Simulation Studies on Porous Medium Integrated Dual Purpose Solar Collector', 3, 1, (2013).

8. J. Ma et al., 'The thermal behavior of a dual-function solar collector integrated with building: An experimental and numerical study on the air heating mode', Energies, 11, 9, (2018).

9. D. Zhang, J. Li, Z. Gao, L. Wang, and J. Nan, 'Thermal performance investigation of modified flat plate solar collector with dual-function', Appl. Therm. Eng. 5, 108, (2016).

10. T. Rajaseenivasan and K. Srithar, 'Potential of a dual purpose solar collector on humidification dehumidification desalination system', Desalination, 28, 404. (2017). 